\title{
Enhanced Hypoxia-Inducible Factor (HIF)- $1 \alpha$ Stability Induced by 5-Hydroxymethyl-2-Furfural (5-HMF) Contributes to Protection against Hypoxia
}

\author{
Yun-Ling He, ${ }^{1^{*}}$ Ming-Ming Li ${ }^{1,{ }^{*}}{ }^{*}$ Li-Ying Wu, ${ }^{1}$ Tong Zhao, ${ }^{1}$ Yao Di, ${ }^{1}$ Xin Huang, ${ }^{1}$ Xue-Feng Ding, ${ }^{1}$ \\ Kui-Wu Wu, ${ }^{1}$ Ming Fan, ${ }^{1,2}$ and Ling-Ling Zhu ${ }^{1}$ \\ ${ }^{1}$ Department of Cognitive Science, Beijing Institute of Basic Medical Sciences, Beijing, China; and ${ }^{2}$ Beijing Institute for Brain \\ Disorders, Beijing, China
}

\begin{abstract}
We first reported the role of 5-hydroxymethyl-2-furfural (5-HMF) against hypoxia. Here, we studied the mechanism by using oxygen-dependent degradation domain (ODD)-Luc mice, which are a useful model to probe the stabilization of hypoxiainducible factor $1 \alpha(\mathrm{HIF-1} \alpha)$. Compared with three other compounds that have been reported to have a role in stabilizing $\mathrm{HIF-1} \alpha$, 5-HMF caused stronger bioluminescence, which is indicative of HIF- $1 \alpha$ stability in the brain and kidney of ODD-Luc mice. We further demonstrated that the HIF-1 $\alpha$ protein accumulated in response to 5-HMF in the brains and kidneys of these mice, as well as in PC12 cells. Additionally, 5-HMF promoted the nuclear translocation of HIF-1 $\alpha$ and the transcriptional activity of HIF-1, which was evaluated by detecting vascular endothelial growth factor (VEGF) mRNA expression. These results suggest that 5-HMF stabilized $\mathrm{HIF}-1 \alpha$ and increased its activity. Considering the role of proline hydroxylases (PHDs) in negatively regulating HIF- $1 \alpha$ stability, we explored whether 5-HMF interacts with the substrates and cofactors of PHDs, such as 2-oxoglutarate (2-OG), Fe ${ }^{2+}$ and vitamin C (VC), which affects the activity of PHDs. The result revealed that 5-HMF did not interact with Fe ${ }^{2+}$ or 2-OG but interacted with VC. This interaction was confirmed by subsequent experiments, in which 5-HMF entered into cells and reduced the VC content. The enhanced stability of HIF- $1 \alpha$ by 5-HMF was reversed by VC supplementation, and the improved survival of mice caused by 5 -HMF under hypoxia was abrogated by VC supplementation. Thus, we demonstrated for the first time that 5-HMF increases HIF- $1 \alpha$ stability by reducing the VC content, which mediates the protection against hypoxia.
\end{abstract}

Online address: http://www.molmed.org

doi: 10.2119/molmed.2014.00007

\section{INTRODUCTION}

Hypoxia is particularly damaging in the brain, where an oxygen deficiency can lead to stroke, cerebral palsy and epilepsy (1-4). For the threat of hypoxia, prevention is far more important than treatment. In our recent study, we identified 5-hydroxymethyl-2-furfural (5-HMF) as a potential preventive drug against hypoxic diseases $(5,6)$.

*Y-LH and M-ML contributed equally to this work.

Address correspondence to Ling-Ling Zhu, Department of Cognitive Science, Beijing Institute of Basic Medical Sciences, 27 Taiping Road, Beijing, 100850 P.R. China. Phone: $+8610-$ 66931315; Fax: +8610-68213039; E-mail: linglingzhu@hotmail.com; or Li-Ying Wu, Department of Cognitive Science, Beijing Institute of Basic Medical Sciences, 27 Taiping Road, Beijing, 100850 P.R. China. Phone: +8610-66931316; Fax: +8610-68213039; E-mail: liyingwu_china@163.com; or Ming Fan, Department of Cognitive Science, Beijing Institute of Basic Medical Sciences, 27 Taiping Road, Beijing, 100850 P.R. China. Phone: +861066932333; Fax: +8610-68213039; E-mail: fanmingchina@126.com.

Submitted January 12, 2014; Accepted for publication October 9, 2014; Epub (www.molmed.org) ahead of print October 10, 2014.

The Feinstein Institute for Medical Research Empowering Imagination. Pioneering Discovery.

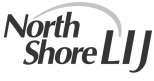

Shore Ll]
5-HMF is a product of the Maillard reaction and exists in plants, foods and beverages that contain carbohydrates, such as the roots of Polygonum multiflorum, dried fruits, bread, fruit juices, milk and coffee $(7,8)$. The beneficial roles of 5-HMF include antioxidant activity, the inhibition of red blood cell sickling and the amelioration of hemorheology (4,9-12). Among these benefits, the role of antisickling, as indicated by the high affinity of 5-HMF for sickle cell hemoglobin, has been granted a U.S. patent (patent number 7119208). We first reported the role of 5 -HMF in protecting against hypoxia in $2011(5,6)$. Nevertheless, the underlying mechanisms have not yet been elucidated. In this study, we demonstrated for the first time that 5-HMF stabilizes hypoxiainducible factor $1 \alpha(\mathrm{HIF}-1 \alpha)$ through an interaction with $\mathrm{VC}$, which mediates the protection of 5-HMF against hypoxia. 
HIF- $1 \alpha$ is a subunit of hypoxiainducible factor 1 (HIF-1) and determines HIF-1 activity. Under normoxia, HIF-1 $\alpha$ is extremely unstable and is quickly degraded by the ubiquitin-proteasome system. Proline hydroxylases (PHDs) (also known as HIF prolyl hydroxylases [HPH]) use $\mathrm{O}_{2}$ and 2-oxoglutarate (2-OG) (also called $\alpha$-ketoglutarate) as substrates and $\mathrm{Fe}^{2+}$ and vitamin C (VC) (also called ascorbic acid) as cofactors hydroxylate prolyl sites at residues 402 and 564 in the oxygen-dependent degradation domain (ODD) of HIF-1 $\alpha$. Then, the tumor suppressor protein von Hippel-Lindau (VHL), which is an E3 ubiquitin ligase complex, recognizes hydroxylated HIF$1 \alpha$, and after polyubiquitination by ubiquitins, HIF-1 $\alpha$ is marked for destruction and is ultimately degraded by hydrolases in proteasomes (13-15). Thus, it can be inferred that the reduction of $\mathrm{O}_{2}$, 2-OG, $\mathrm{Fe}^{2+}$ or VC will inhibit the activities of PHDs and then elevate HIF-1 $\alpha$ stability. For example, under hypoxia, HIF-1 $\alpha$ becomes stable because of a lack of $\mathrm{O}_{2}$ as a substrate of PHDs and, therefore, accumulates its protein. Subsequently, HIF- $1 \alpha$ translocates from the cytoplasm into the nucleus and heterodimerizes with constitutively expressed HIF-1 $\beta$, which is another HIF-1 subunit, to form the heterodimeric transcription factor HIF-1. HIF-1 binds to a conserved hypoxia-response element (HRE), which contains the core nucleotide sequence 5'-(A/G) CGTG-3' in the promoter region of its target genes, to activate the transcription of HIF-1 target genes. HIF-1 target genes include vascular endothelial growth factor (VEGF), erythropoietin (EPO), glucose transporters (GLUTs), BCL2/adenovirus E1B $19 \mathrm{kd}$-interacting protein 3 (BNIP3)/ BNIP3-like (BNIP3L), miRNAs, and so on, which mediate the adaptation to hypoxic stress (16-18).

From the above description, we can easily draw an inference that the stability of HIF-1 $\alpha$ determines the hypoxic adaptation. Therefore, drugs that target HIF- $1 \alpha$ have the potential to prevent hypoxic diseases. Unfortunately, there is a lack of drugs to stabilize HIF-1 $\alpha$ under normoxia and to prevent hypoxic injury. In our previous studies, we confirmed the protective role of 5-HMF against hypoxic injury in mice and in ECV304 cells $(5,6)$. However, whether the role is correlated to HIF- $1 \alpha$ stability is unknown. In this study, using ODD-Luc transgenic mice to evaluate agents that stabilize HIF-1 $\alpha$, we demonstrated for the first time that 5-HMF stabilizes HIF-1 $\alpha$ under normoxia by reducing the VC content, and this effect is relieved by VC supplementation. Thus, 5-HMF has the potential to be developed as a drug to prevent hypoxic diseases in the future.

\section{MATERIALS AND METHODS}

\section{Materials}

5-HMF, ferulic acid, coumarin, quercetin, $\mathrm{CoCl}_{2}$ and ascorbate oxidase were purchased from Sigma-Aldrich (St. Louis, MO, USA). Luciferin was obtained from Promega (Madison, WI, USA). The HIF-1 $\alpha$ mouse monoclonal antibody was purchased from Novus Biologicals (Littleton, CO, USA). The mouse $\beta$-actin monoclonal antibody was acquired from Sigma-Aldrich. The rabbit Pro564-OH polyclonal antibody was purchased from Cell Signaling Technology (Boston, MA, USA). The Alexa 594 goat anti-mouse secondary antibody and 4',6-diamidino-2-phenylindole (DAPI) were Molecular Probes products (Thermo Fisher Scientific, Waltham, MA, USA).

\section{Animals}

The ODD-Luc mice were acquired from The Jackson Laboratory (Bar Harbor, ME, USA). This mouse model expresses the oxygen-dependent degradation (ODD) domain of HIF-1 $\alpha$ fused to the firefly luciferase gene. Fusing the ODD domain to luciferase renders the luciferase protein sensitive to oxygendependent hydroxylation and to subsequent ubiquitin-dependent degradation under normal physiological circumstances. The advantage of ODD-Luc mice is that these mice can provide a rapid noninvasive measurement of possible agonists of HIF-1 activity (19).

C57BL/6J male mice were purchased from the Animal Central of Academy of Military Medical Science (Beijing, China) and were used for survival experiments under hypoxia conditions. The animal protocol was approved by the Institutional Animal Care and Use Committee of the Academy of Military Medical Science and was consistent with the National Institutes of Health (NIH) Guide for the Care and Use of Laboratory Animals (NIH publications no. 85-23) (20).

\section{Cell Culture}

The PC12 cell line was obtained from the American Type Culture Collection (ATCC, Manassas, VA, USA). PC12 cells are a neuronal cell line derived from a rat pheochromocytoma, and these cells are often used as a model for neurons and a model for hypoxia because of their sensitivity to hypoxia. As described previously (19), briefly, cells were cultured in 75- $\mathrm{cm}^{2}$ tissue culture flasks (Corning, NY, USA) in Dulbecco's modified Eagle medium (DMEM) (Gibco [Thermo Fisher Scientific]) and were maintained in DMEM containing $5 \%$ newborn calf serum and $10 \%$ horse serum supplemented with $100 \mathrm{U} / \mathrm{mL}$ penicillin and $100 \mathrm{pg} / \mathrm{mL}$ streptomycin in a moist atmosphere of $5 \% \mathrm{CO}_{2}$ at $37^{\circ} \mathrm{C}$. Experiments were performed 1-2 d after plating.

\section{Luciferase Expression in ODD-Luc Mice}

ODD-Luc mice were given an intraperitoneal injection of 5- $\mathrm{HMF}, \mathrm{CoCl}_{2}$, ferulic acid, coumarin, quercetin or vehicle. One hour later, luciferin (50 mg/kg), which is a substrate of luciferase, was intraperitoneally injected into each mouse. Then, 5 min later, the mice were anesthetized by isoflurane for $5 \mathrm{~min}$ and then placed in a light-tight chamber equipped with an IVIS imaging camera (IVIS 50; Xenogen, Alameda, CA, USA). Photons were collected for a period of 10-30 s, and images were obtained and analyzed by using the Living Image software (Xenogen). 


\section{Hypoxia Treatment and Animal Survival}

C57BL/6J mice were used to detect the effect of 5-HMF or VC on animal survival under a hypoxia environment. The mice were pretreated with 5-HMF $(100 \mathrm{mg} / \mathrm{kg})$, VC (140 mg/kg) or vehicle (normal saline) by intraperitoneal injection for $1 \mathrm{~h}$ and then supplemented with vehicles or VC $(140 \mathrm{mg} / \mathrm{kg})$ for another $1 \mathrm{~h}$. After that, they were placed in a hypoxia chamber (DYC-DWI; Guizhou Fenglei, Guizhou, China) containing 20\% $\mathrm{O}_{2}$. For sublethal acute hypoxia, the oxygen levels were decreased at a velocity of approximately $1-2 \% \mathrm{O}_{2} / \mathrm{min}$ and reached $6 \% \mathrm{O}_{2}$ within $10 \mathrm{~min}$. After exposed to hypoxia, animal survival was recorded. The survival time was defined with $10 \mathrm{~min}$ as the threshold value. The mice that lived over $10 \mathrm{~min}$ under hypoxia were considered survivors. Survival rate $(\%)=$ the number of mice that lived over $10 \mathrm{~min} /$ total number of mice.

\section{Western Blot Analysis}

The cortices and kidneys of ODD-Luc mice or PC12 cells were harvested, and the total proteins were extracted with radioimmunoprecipitation assay lysis buffer, which contained $50 \mathrm{mmol} / \mathrm{L}$ Tris$\mathrm{HCl}$ (pH 7.4), 1\% NP-40, 0.25\% Nadeoxycholate, $150 \mathrm{mmol} / \mathrm{L} \mathrm{NaCl}$ and $0.1 \%$ sodium dodecyl sulfate (SDS) supplemented with protease inhibitors (Roche, Indianapolis, IN, USA) and $1 \mathrm{mmol} / \mathrm{L}$ PMSF. The lysates were quantified by using a protein assay kit (Bio-Rad Laboratories, Hercules, CA, USA), separated by SDS-polyacrylamide gel electrophoresis (SDS-PAGE) and transferred to a polyvinylpyrrolidone difluoride membrane (Millipore, Billerica, MA, USA). After blocking with 5\% nonfat dry milk in Tris-buffered saline with Tween-20 (TBST) at room temperature for $1 \mathrm{~h}$, membranes were incubated with a HIF-1 $\alpha$ mouse monoclonal antibody $(1: 1,000$; Novus Biologicals) and with a $\beta$-actin mouse monoclonal antibody (1:5,000; Sigma-Aldrich) in TBST, which contained $5 \%$ nonfat dry milk, at $4^{\circ} \mathrm{C}$ overnight. This overnight incubation was followed by incubation with a goat anti-mouse secondary antibody, which was conjugated with horseradish peroxidase $(1: 1,000$; Santa Cruz Biotechnology, Santa Cruz, CA, USA) in TBST, which contained 5\% nonfat dry milk. Immune complexes on the membrane were visualized by using an enhanced chemiluminescence (ECL) detection system (Amersham Biosciences, Piscataway, NJ, USA). $\beta$-actin was used as a loading control. Experiments were repeated at least three times. Scans were used for semiquantitative analysis.

\section{Immunofluorescence Staining}

Cells that were grown on glass coverslips were fixed with methanol at $-20^{\circ} \mathrm{C}$ for $20 \mathrm{~min}$ and permeabilized with $0.5 \%$ Triton X-100 at room temperature for 30 min. After blocking nonspecific binding with 5\% normal goat serum in PBS-0.3\% Triton $\mathrm{X}-100$ at room temperature for $1 \mathrm{~h}$, the cells were incubated with an anti-HIF-1 $\alpha$ antibody (1:500; Novus Biologicals). The primary antibody was detected by incubation with an Alexa Flour 594 goat anti-mouse secondary antibody (1:500; Molecular Probes [Thermo Fisher Scientific]) at room temperature for $1 \mathrm{~h}$. All incubations were performed in a humidified chamber. The cells were visualized and photographed by using a confocal microscope (Leica TCS SP5; Leica, Heidelberg, Germany).

\section{Reverse-Transcription-Polymerase Chain Reaction (RT-PCR)}

For the analysis of VEGF mRNA, total RNA isolated from the cortices and kidneys of ODD-Luc mice was prepared by using the TRIzol ${ }^{\circledR}$ reagent (Invitrogen [Thermo Fisher Scientific]) according to the manufacturer's instructions. Total RNA $(2 \mu \mathrm{g})$ was amplified by a two-step protocol by using M-MLV reverse transcriptase and Taq polymerase. The PCR products were amplified by using the following program: primers for VEGF (forward: 5'-GACCCTGGTGGACATCTT-3', reverse: 5'-TAGTTCCCGAAACCCTGA$3^{\prime}$ ) were used to yield a 452-base pair (bp) product for 28 cycles at $58^{\circ} \mathrm{C} ; 18 \mathrm{~S}$ rRNA primers (forward: 5'-GCCCG
AAGCGTTTACTTTGAA-3', reverse: 5'GGTGAGGTTTCCCGTGTTGA-3') were used to yield a 459-bp product for $28 \mathrm{cy}-$ cles at $56^{\circ} \mathrm{C}$. The mRNA expression level was semiquantified relative to the endogenous expression level of $18 \mathrm{~S}$ rRNA as an internal control. PCR products were separated on a $1.5 \%(\mathrm{w} / \mathrm{v})$ agarose gel and visualized by ethidium bromide staining. The images were acquired by using a MultiImage Light Cabinet (Alpha Innotech, San Leandro, CA, USA).

\section{Quantitative Real-time PCR (qRT-PCR)}

The mRNA levels of HIF- $1 \alpha$ and $\beta$-actin were measured using Power SYBR ${ }^{\circledR}$ Green (Applied Biosystems [Thermo Fisher Scientific]) and an ABI StepOnePlus RealTime PCR System (Applied Biosystems [Thermo Fisher Scientific]) according to the manufacturer's instructions. Total RNA was isolated from PC12 cells by using the TRIzol ${ }^{\circledR}$ Reagent and performed according to the manufacturer's protocol. An aliquot of $1 \mu \mathrm{g}$ total mRNA was reverse-transcribed at $42^{\circ} \mathrm{C}$ for $1 \mathrm{~h}$ in a $10-\mu \mathrm{L}$ reaction mixture. The qRT-PCR was performed in triplicate by using Power $\mathrm{SYBR}^{\circledR}$ Green and a real-time PCR system. The following HIF-1 $\alpha$ primers were used: forward 5'-CCGCAGTGTGGCTAC AAGAA-3', reverse 5'-GATGAGGAAT GGGTTCACAAATC-3', 67 bp. The results were normalized by using $\beta$-actin as the internal control, with the following primers: forward 5'-CCAGTTCGCC ATGGATGAC-3', reverse 5'-ATGCC GGAGCCGTTGTC-3', 87 bp. Calculations were based on the "delta-delta method" by using the following equation: $R$ (ratio) $=2^{-[\Delta C \mathrm{CT} \text { sample }-\Delta \mathrm{CT} \text { control] }}(21)$. The data were expressed as fold changes of the treatment groups relative to the control. $\beta$-actin was amplified as an internal control for qRT-PCR analysis.

\section{Ultraviolet-Visible Spectroscopy Analysis}

To detect the interaction of 5-HMF with $\mathrm{Fe}^{2+}\left(\mathrm{FeSO}_{4}\right)$, 2-OG or VC, an ultraviolet (UV)-visible spectrophotometer (Multiskan Go; Thermo Scientific [Thermo Fisher Scientific]) was used for the analy- 
A

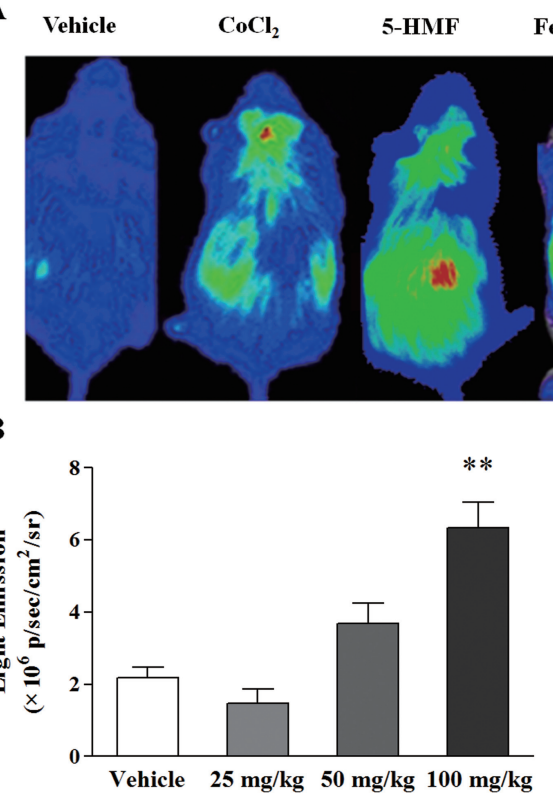

D

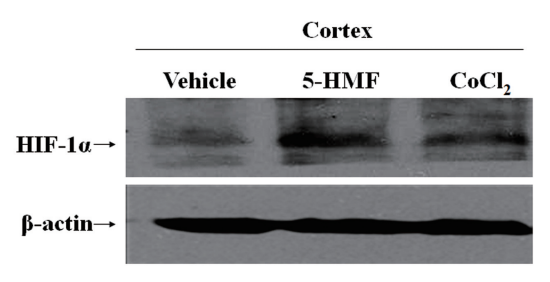

$\mathbf{E}$

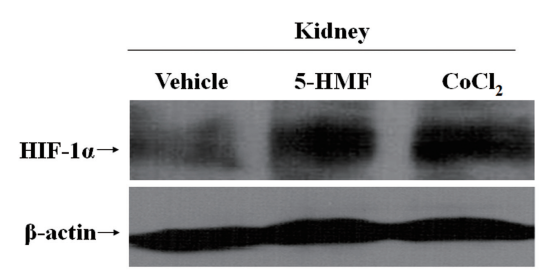

Coumarin Quercetin

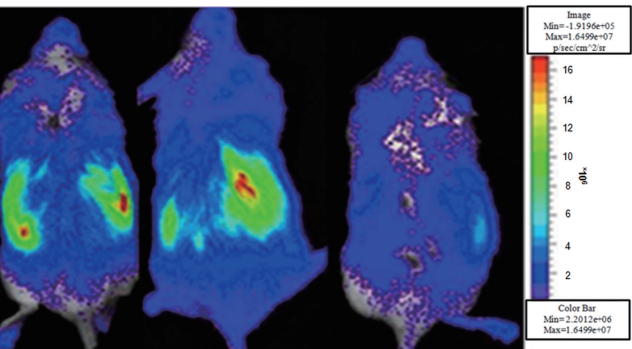

C
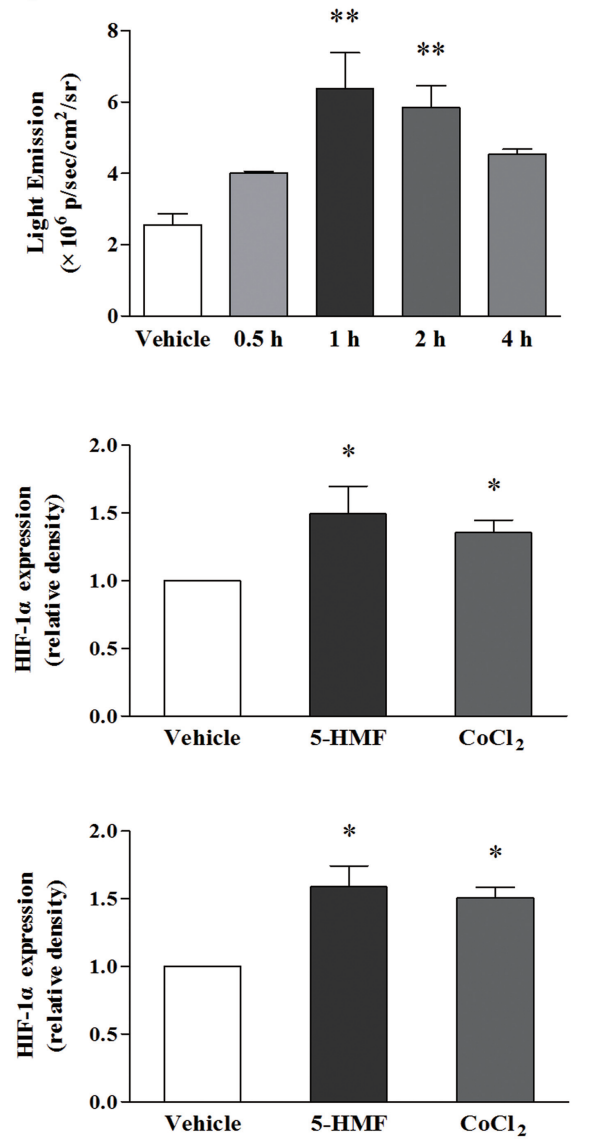

Figure 1. The stabilization effect of 5-HMF on HIF-1 $\alpha$ in ODD-Luc mice. (A) Comparison of the bioluminescence among anti-oxidative agents. The intensity of bioluminescence indicates the degree of HIF-1 $\alpha$ stability. The ODD-Luc mice were given an intraperitoneal injection of vehicle (normal saline), $\mathrm{CoCl}_{2}(125 \mathrm{mg} / \mathrm{kg}), 5-\mathrm{HMF}(100 \mathrm{mg} / \mathrm{kg})$, ferulic acid (100 mg/kg), coumarin (100 mg/kg) or quercetin (100 mg/kg). The color bar indicates photons/(s/ $\mathrm{cm}^{2} /$ steradian), with minimum and maximum threshold values. (B, C) Determination of the dose and time effect of 5-HMF on HIF- $1 \alpha$ stability. The left panel shows the bioluminescence intensity $1 \mathrm{~h}$ after the mice were treated with different concentrations of 5-HMF. The right panel shows the bioluminescence intensity at 0.5, 1, 2, and $4 \mathrm{~h}$ after the mice were treated with $100 \mathrm{mg} / \mathrm{kg}$ of $5-\mathrm{HMF}$. The data that are shown are the means \pm SE of three independent experiments. ${ }^{* *} p<0.01$ compared with the vehicle. (D, E) Western blot analysis of HIF- $1 \alpha$ protein expression in the cortex and kidney tissues of ODD-Luc mice. Whole-cell lysates were subjected to an immunoblot assay for HIF- $1 \alpha$ and $\beta$-actin. $\beta$-actin was used as an internal control. The values were normalized to the vehicle levels. The results are the means \pm SE of four independent experiments. ${ }^{*} p<0.05$ compared with the vehicle.

ses. The solution of $20 \mu \mathrm{mol} / \mathrm{L} 5-\mathrm{HMF}$ and $0,2.5,5,10,15$ or $20 \mu \mathrm{mol} / \mathrm{L} \mathrm{FeSO}_{4}$, 2-OG or VC was mixed and incubated for $2 \mathrm{~min}$ at room temperature. Spectra were collected in the range of 200- to 500-nm wavelengths. The maximum UV absorptivity of 5-HMF is $285 \mathrm{~nm}$.

To determine the VC content in the cytoplasm, sample preparation and measurements, as described previously in the literature $(22,23)$, were as follows: briefly, after PC12 cells were treated with 5-HMF, the cells were permeabilized with $0.5 \%$ Triton X-100 in phosphatebuffered saline (PBS) for $10 \mathrm{~min}$, and the supernatant was collected. Then, $200 \mu \mathrm{L}$ of the supernatant was added to $1 \mathrm{~mL}$ $0.1 \mathrm{mmol} / \mathrm{L} \mathrm{NaH}_{2} \mathrm{PO}_{4}(\mathrm{pH} 5.6)$ and $750 \mu \mathrm{L}$ ultrapure water and mixed. The absorbance at $265 \mathrm{~nm}\left(\mathrm{~A}_{265}\right)$ was measured by using a spectrophotometer, followed by incubation with ascorbate oxidase (0.4 U, pH 5.6) for $3 \mathrm{~min}$ and measured again. The decrease in $\mathrm{A}_{265}$ was monitored. The VC content was calculated based on the decrease in $\mathrm{A}_{265}$.

\section{High-Performance Liquid Chromatography (HPLC) Analysis of 5-HMF Content}

The stock solution of 5-HMF ( $4 \mu \mathrm{mol} / \mathrm{L})$ was prepared by dissolving $25.22 \mathrm{mg}$ 5-HMF in $50 \mathrm{~mL}$ ultrapure water and stored at $4^{\circ} \mathrm{C}$. Five concentrations of 5 -HMF standard solutions $(0.02,0.10,0.50$, 2.52 and $12.61 \mathrm{mg} / 100 \mathrm{~mL}$ ) were obtained by appropriately diluting the stock solution with mobile phase and were used to evaluate the linearity of the HPLC data (HP1100; Agilent, Burnsville, MN, USA). Chromatographic separation was performed by using a Diamonsil C18 column (250 × $4.6 \mathrm{~mm}$ inside diameter [i.d.], $5 \mu \mathrm{m}$; Dikma, Lake Forest, CA, USA). The mobile phase was a mixture of ultrapure water to acetonitrile (95:5, v/v) and was delivered at a flow rate of $1.0 \mathrm{~mL} / \mathrm{min}$. The detection wavelength was $285 \mathrm{~nm}$.

\section{Statistical Analysis}

Statistical analysis was performed by using the SPSS software. All the data were expressed as the means \pm standard 
error (SE). A comparison between two samples was performed using a two-tail Student $t$ test. $p<0.05$ was considered statistically significant.

\section{RESULTS}

\section{5-HMF Increased HIF- $1 \alpha$ Stability in a Dose- and Time-Dependent Manner in ODD-Luc Transgenic Mice}

Using ODD-Luc transgenic mice, which are a useful model to probe the stabilization of HIF- $1 \alpha$, we compared the effect of 5-HMF and the other three confirmed compounds that can stabilize HIF-1 $\alpha$. Cobalt chloride $\left(\mathrm{CoCl}_{2}\right)$, which is an iron antagonist, was used as a positive control. Compared with ferulic acid, coumarin and quercetin, 5-HMF caused stronger bioluminescence in the brain and kidney areas (Figure 1A), which indicated a stronger role of 5-HMF in stabilizing HIF-1 $\alpha$. In addition, 5-HMF stabilized HIF- $1 \alpha$ in a dose- and time-dependent manner in ODD-Luc mice (Figures 1B, C). To further verify this effect of 5-HMF on HIF-1 $\alpha$ stability, we measured HIF-1 $\alpha$ protein expression in the cortices (Figure 1D) and kidneys (Figure 1E) of ODD-Luc mice by Western blot. Consistent with the result of the bioluminescent assay, 5-HMF accumulated the HIF- $1 \alpha$ protein in both tissues.

\section{5-HMF Promoted HIF- $1 \alpha$ Stability and Nuclear Translocation in PC12 Cells}

In hypoxia-sensitive PC12 cells, the role of 5-HMF in accumulating HIF-1 $\alpha$ was further determined. Through comparing HIF-1 $\alpha$ protein levels $1 \mathrm{~h}$ after cells were treated with different concentrations of 5-HMF, we identified the role of $100 \mu \mathrm{g} / \mathrm{mL} 5$-HMF in the accumulation of HIF-1 $\alpha$ (Figure 2A). To identify whether this accumulating effect of 5 -HMF on the HIF-1 $\alpha$ protein is due to promoting HIF-1 $\alpha$ stability or to increasing HIF-1 $\alpha$ transcription, we measured the mRNA expression of HIF-1 $\alpha$ by real-time PCR. Although there was a subtle trend of increasing HIF-1 $\alpha$ mRNA with increasing 5-HMF dosage, there were no significant differences

A

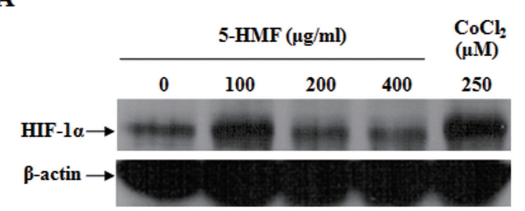

B

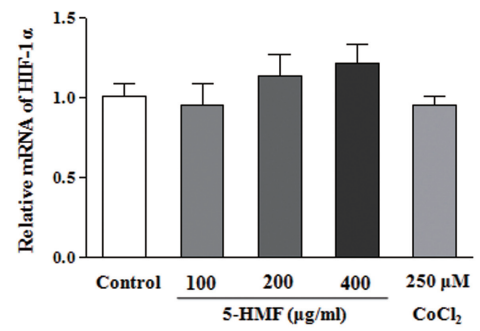

D
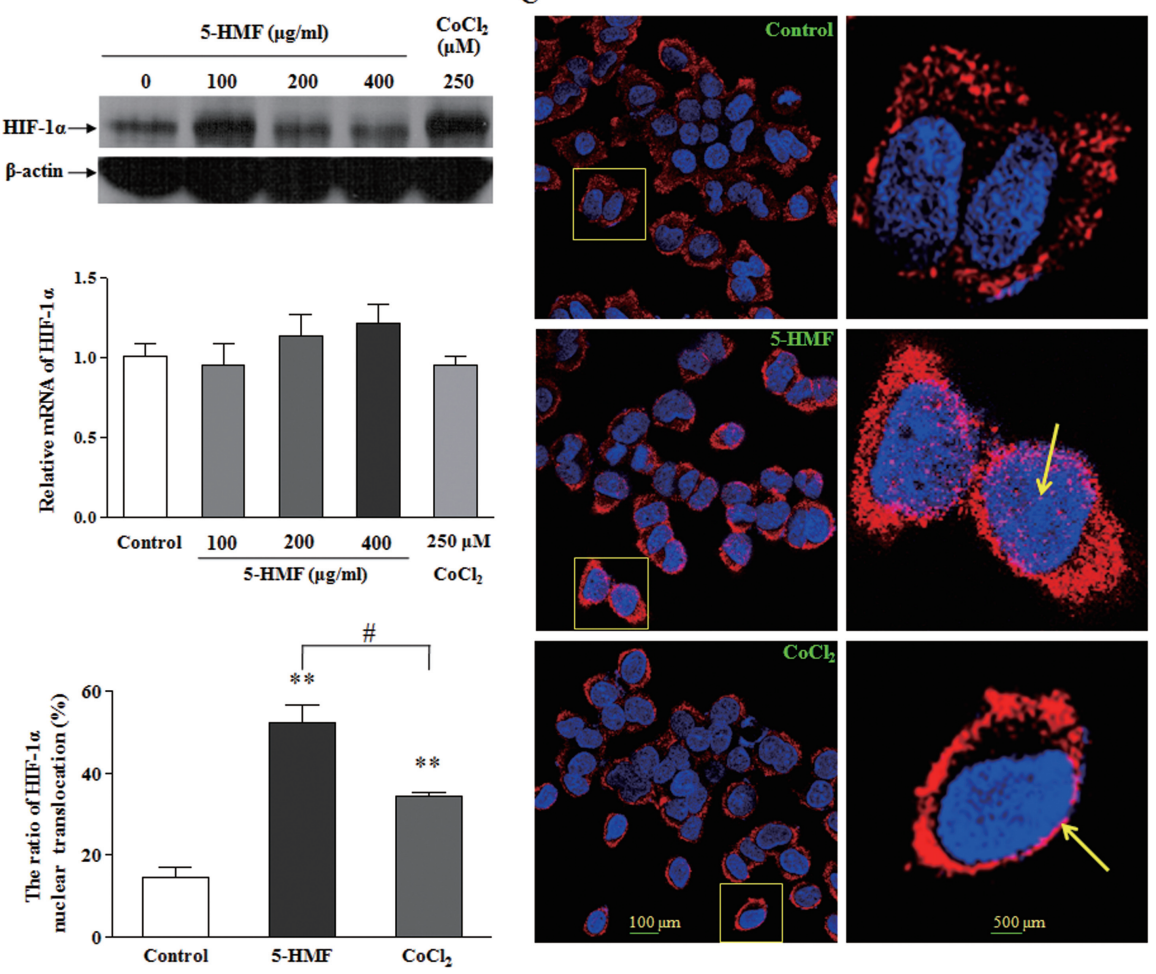

Figure 2. The increased stability and nuclear translocation of HIF-1 $\alpha$ by 5-HMF in PC12 cells. (A) Effects of 5-HMF on the levels of the HIF-1 $\alpha$ protein. PC12 cells were exposed to the indicated concentrations of $5-\mathrm{HMF}$ or $\mathrm{CoCl}_{2}$ for $1 \mathrm{~h}$. The representative immunoblots are shown. (B) Effects of 5-HMF on the levels of HIF-l $\alpha$ mRNA. The HIF- $1 \alpha$ mRNA levels were determined by qRT-PCR analysis after cells were treated for $1 \mathrm{~h}$. The relative expressions were normalized to the control level. (C) Effects of 5-HMF on the nuclear translocation of HIF- $1 \alpha$. The distribution of the HIF-l $\alpha$ protein was analyzed with immunofluorescence staining after the cells were treated with $100 \mu \mathrm{g} / \mathrm{mL} 5$-HMF for $1 \mathrm{~h}$. The cells were labeled for HIF- $1 \alpha$ (red) and counterstained with DAPI (blue), which was used to label nuclei. The arrowheads indicate the nuclear localization of $\mathrm{HIF}-1 \alpha$, which was stained pink. The image at the right panel is the enlarged image in the frame at the left. (D) Statistical analysis of the ratio of HIF- $1 \alpha$ nuclear translocation. The ratio was calculated in terms of the following formula: HIF-l $\alpha$ nuclear translocation $(\%)=$ (the number of cells with pink/the total number of cells with red) $\times 100$. The results are expressed as the means \pm SE from three independent experiments. ${ }^{* *} P<0.01$ compared with the control; $" p<0.05$ for comparisons between the indicated groups.

compared with the control. Therefore, 5-HMF did not cause an obvious increase in the HIF-1 $\alpha$ mRNA level (Figure $2 \mathrm{~B})$. This result suggests that the higher level of the HIF-1 $\alpha$ protein that was induced by 5-HMF was due to the stabilization of the HIF- $1 \alpha$ protein in normoxia rather than by the promotion of its de novo protein synthesis.

By immunofluorescence staining, we observed that HIF-1 $\alpha$ gathered to the nucleus and partly entered into the nucleus in the cells that were treated with
5-HMF; in contrast, HIF-1 $\alpha$ was scattered in the cytoplasm in the control (Figure 2C). By counting the number of cells where HIF-1 $\alpha$ entered into their nuclei and the total number of cells that expressed HIF-1 $\alpha$, we obtained the ratio of HIF-1 $\alpha$ nuclear translocation. The statistical data revealed that 5-HMF significantly increased the ratio of HIF-1 $\alpha$ nuclear translocation (Figure 2D). In short, the above results show that 5-HMF promotes HIF-1 $\alpha$ stability and its nuclear translocation. 
$\mathbf{A}$

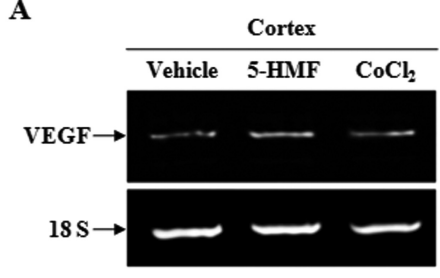

B

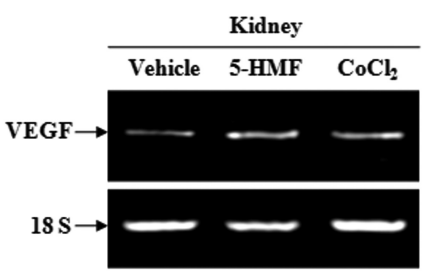

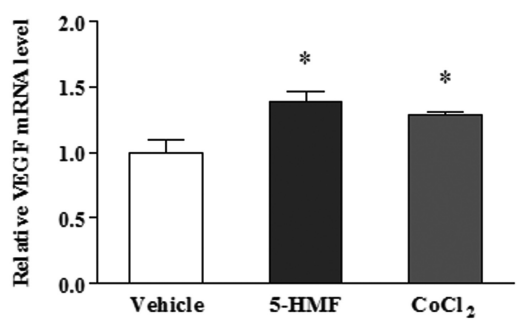

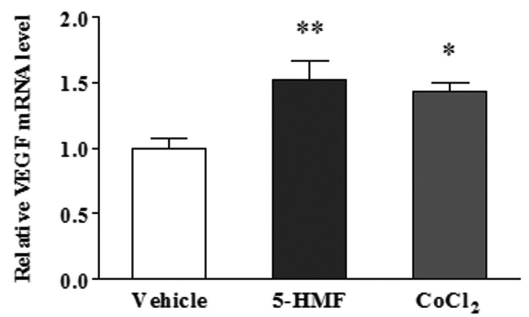

Figure 3. The enhanced VEGF mRNA expression by 5-HMF in ODD-Luc mice. (A, B) Effects of 5-HMF on the VEGF mRNA expression in the cortex and in the kidney. The transcriptional activity of HIF-1 was estimated by VEGF mRNA expression. The VEGF mRNA levels were analyzed by semiquantitative RT-PCR. Tissues were harvested for RT-PCR $1 \mathrm{~h}$ after the ODD-Luc mice were given an intraperitoneal injection of vehicle (normal saline), 5-HMF (100 mg/kg) or $\mathrm{CoCl}_{2}(125 \mathrm{mg} / \mathrm{kg})$. 18S rRNA was used as an internal control. The values were normalized to the vehicle levels. The data are representative of four different experiments and are expressed as the means \pm SE. ${ }^{*} p<0.05,{ }^{* *} p<0.01$, compared with the vehicle.

\section{5-HMF Increased HIF-1 Transcriptional Activity by the Induction of VEGF mRNA Expression in ODD-Luc Transgenic Mice}

To determine the effect of 5-HMF on HIF-1 transcriptional activity after stabilizing HIF-1 $\alpha$, we measured the mRNA level of VEGF, which is an HIF-1 target gene, to assess HIF-1 transcriptional activity. After the total mRNA was extracted from the cerebral cortex and kidney of ODD-Luc mice that were treated with $100 \mathrm{mg} / \mathrm{kg} 5$-HMF for $1 \mathrm{~h}$, the expression of VEGF mRNA was measured by RT-PCR. Compared with the vehicle, the levels of VEGF mRNA in the cortex (Figure 3A) and kidney (Figure 3B) were elevated by 5 -HMF, which was consistent with the case of the HIF-1 $\alpha$ protein. This result suggests that 5-HMF increased HIF-1 transcriptional activity.

\section{5-HMF Reacted with VC In Vitro and Reduced the VC Content in PC12 Cells}

How did 5-HMF increase the stability of HIF- $1 \alpha$ ? HIF-1 $\alpha$ stability depends on the activity of PHDs, which is determined by the content of the substrates $\left(\mathrm{O}_{2}, 2-\mathrm{OG}\right)$ or the cofactors $\left(\mathrm{Fe}^{2+}, \mathrm{VC}\right)$ of PHDs. Because 5-HMF increased HIF-1 $\alpha$ stability in normoxia, we considered whether 5-HMF inhibited the activity of PHDs through interacting with 2-OG, $\mathrm{Fe}^{2+}$ or VC. Using UV spectrophotometry, we discovered that different concentrations of $\mathrm{Fe}^{2+}$ or 2-OG did not affect the maximum absorbance wavelength $\left(\lambda_{\max }\right)$ of 5-HMF; however, with increasing VC concentrations, the $\lambda_{\max }$ of 5-HMF decreased (Figure 4A). The correlation curve of the concentration-absorbance difference $(\Delta \mathrm{Abs})$ revealed that there was no correlation between 5-HMF and $\mathrm{Fe}^{2+}$ or 2-OG; however, there was a significant correlation between 5-HMF and VC (Figure 4B), which implied a biochemical reaction between 5-HMF and VC. Thus, we wondered whether 5-HMF could enter cells and affect their VC content. After PC12 cells were treated with 5-HMF for 1 $\mathrm{h}$, the intracellular content of 5-HMF was detected using HPLC. The results showed that the intracellular contents of
5-HMF increased with the extracellular concentrations of 5-HMF (Figure 4C). This result suggests that 5-HMF can enter cells in a dose-dependent fashion. Subsequently, we further detected the VC content in PC12 cells by using UV spectrophotometry after the cells were treated with 5-HMF. The VC content in PC12 cells was significantly reduced by $5-\mathrm{HMF}$ (Figure 4D). These results suggest that 5-HMF reacted with VC in the cells and, therefore, reduced the VC content.

\section{Increased HIF- $1 \alpha$ Stability by 5-HMF Was Reversed by VC Supplementation in PC12 Cells and in ODD-Luc Mice}

To verify that the increased HIF- $1 \alpha$ stability caused by $5-\mathrm{HMF}$ was due to a reduction in the VC content, we measured the hydroxylation level of HIF-1 $\alpha$ Pro-564, which indirectly reflects the activity of PHDs, and the protein level of HIF-1 $\alpha$ in PC12 cells by Western blot. 5-HMF decreased the level of HIF-1 $\alpha$ Pro-564 hydroxylation, whereas VC supplementation returned the protein level of HIF-1 $\alpha$ to the control level (Figure 5A). Similarly, the accumulation of HIF-1 $\alpha$ induced by 5 HMF was also attenuated by VC supplementation (Figure 5B). By using ODD-Luc mice, we observed that 5-HMF induced an increase in bioluminescence, and VC supplementation resulted in a decrease in bioluminescence compared with the effect of 5-HMF (Figure 5C). Altogether, these results indicate that the role of 5-HMF in stabilizing HIF-1 $\alpha$ can be reversed by VC supplementation, which suggests that the stabilization of HIF- $1 \alpha$ by 5 -HMF is mediated by a reduction in the VC content.

\section{Increased Survival of Mice by 5-HMF Under Hypoxia Was Reversed by VC Supplementation}

To elucidate the effect of increased HIF$1 \alpha$ stability by 5 -HMF on mice survival under hypoxia, we compared the survival of mice that were treated with 5-HMF or that were supplemented with VC. The survival time of mice under hypoxia was extended by 5-HMF; in contrast, VC supplementation obviously decreased the survival time (Figure 6A). Simultaneously, the 
$\mathbf{A}$
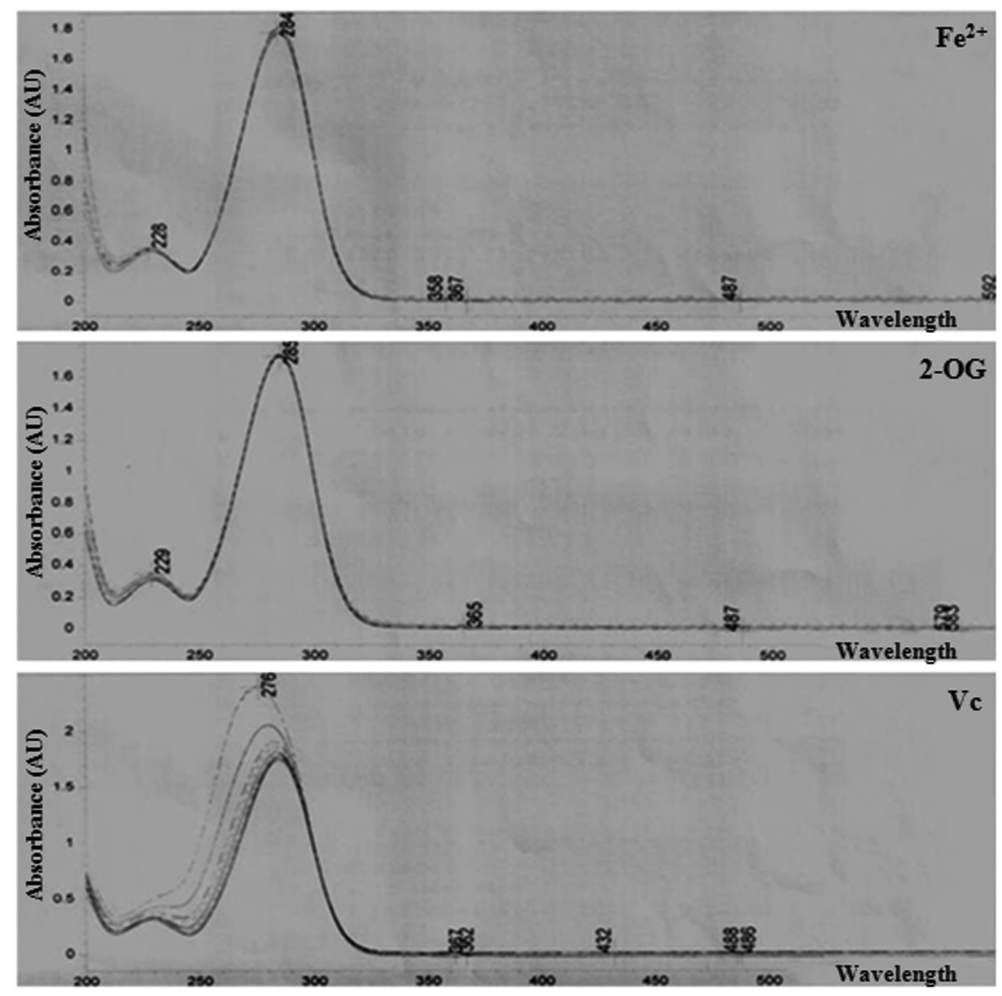

C

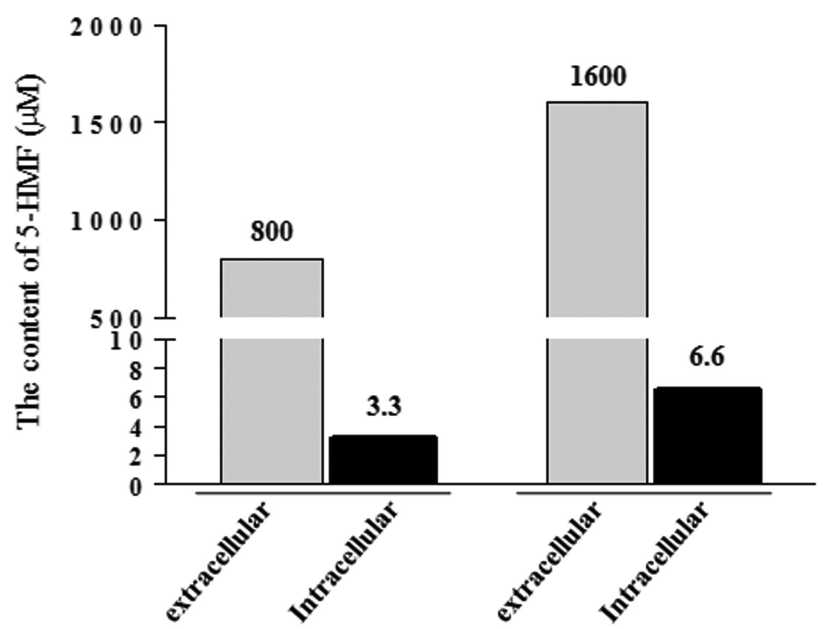

B
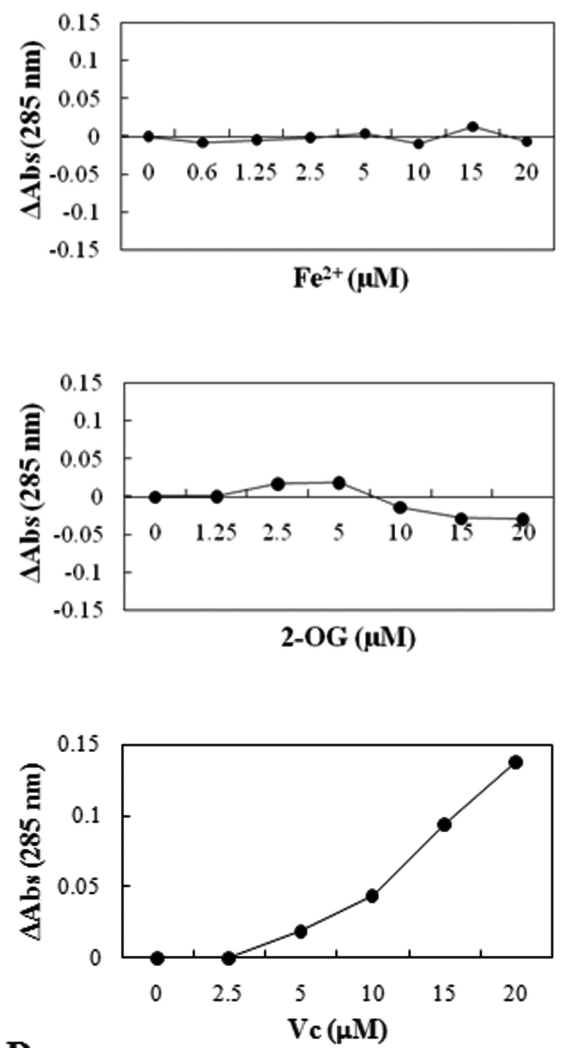

D

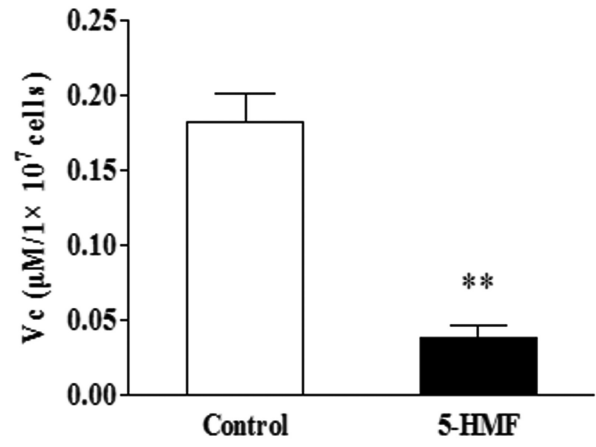

Figure 4. The reaction of 5-HMF and VC in vitro and, thereby, a reduction in the VC content in PC12 cells. (A) The UV-Visible absorption spectra of 5-HMF. A total of $20 \mu \mathrm{mol} / \mathrm{L} 5-\mathrm{HMF}$ in $10 \mathrm{mmol} / \mathrm{L}$ phosphate buffer, $\mathrm{pH} 7.4$, was titrated with increasing concentrations (0, 2.5, 5, 10,15 and $20 \mu \mathrm{mol} / \mathrm{L}$ ) of $\mathrm{Fe}^{2+}, 2-\mathrm{OG}$ or VC in vitro. After incubation for $2 \mathrm{~min}$, the absorption spectra of 5-HMF was obtained from 200 to $500 \mathrm{~nm}$ by UV-visible spectroscopy analysis. The absorption peak of 5-HMF is $285 \mathrm{~nm}$. (B) The correlation curves of concentration and absorbance difference compared with $285 \mathrm{~nm}\left(\Delta \mathrm{abs} 285 \mathrm{~nm}\right.$ ). There is no correlation between 5-HMF and Fe ${ }^{2+}$ or 5-HMF and 2-OG; however, there is a positive correlation between 5-HMF and VC, which indicates the reaction of 5-HMF and VC. (C) Determination of the content of 5-HMF in the intracellular cytoplasm. The content of 5-HMF in PC12 cells was detected by HPLC after the cells were exposed to 5-HMF in the medium for 1 h. 5-HMF was detectable in the cytoplasm, and the content increased with increasing concentrations of extracellular 5-HMF. (D) The reduction of VC content by 5-HMF. The VC content was detected by UV-visible spectroscopy analysis after the cells were exposed to $5-\mathrm{HMF}(100 \mu \mathrm{g} / \mathrm{mL})$ for $1 \mathrm{~h}$. The data are representative of four different experiments and are expressed as the means \pm SE. ${ }^{* *} P<0.01$, compared with the control. 
A

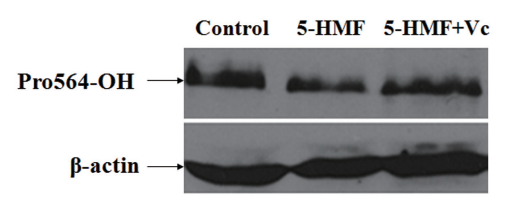

B

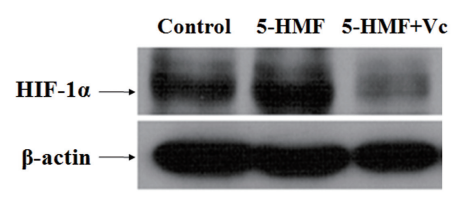

C

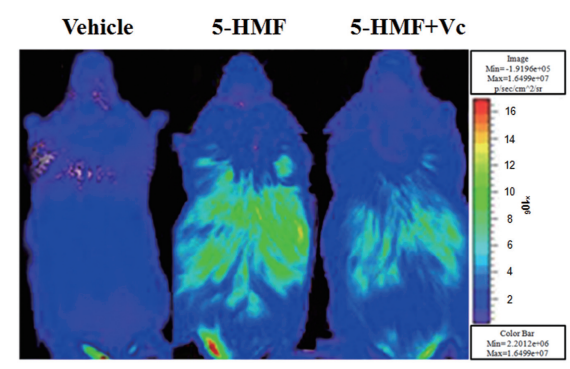

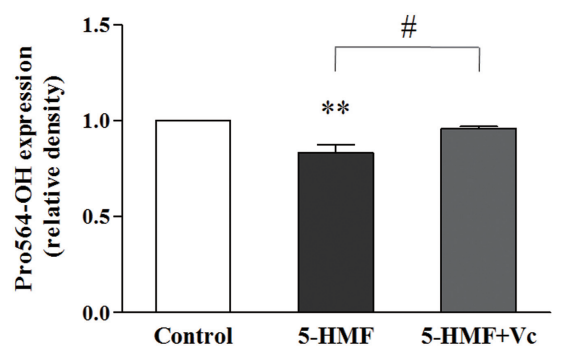
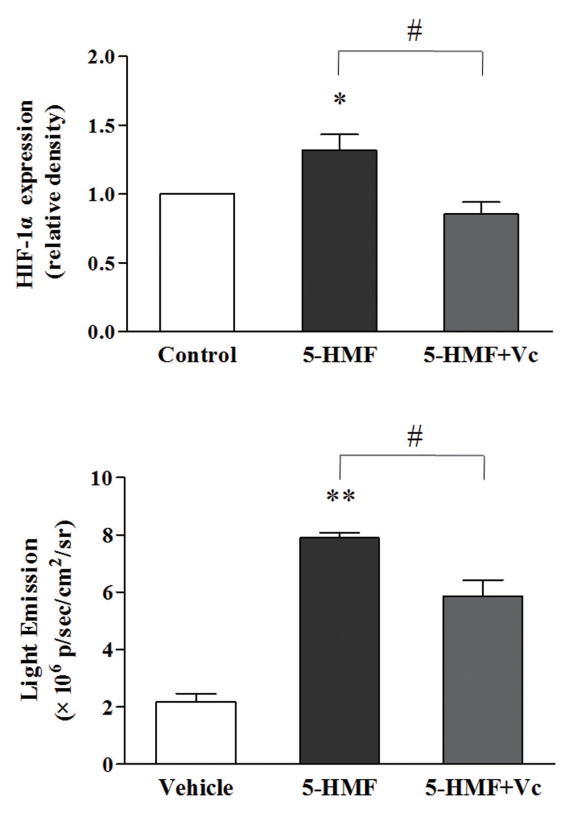

Figure 5. VC reversed the stabilization of $\mathrm{HIF}-1 \alpha$, which was caused by $5-\mathrm{HMF}$, in $\mathrm{PC} 12$ cells and in ODD-Luc mice. (A, B) Western blot analysis of the hydroxylation of HIF-1 $\alpha$ Pro-564 and the HIF-l $\alpha$ protein expression. The levels of HIF- $1 \alpha$ hydroxylation and HIF- $1 \alpha$ protein expression were measured by Western blot after PC 12 cells were exposed to $100 \mu \mathrm{g} / \mathrm{mL} 5$-HMF or culture medium for $1 \mathrm{~h}$, followed by supplementation with culture medium or with $140 \mu \mathrm{g} / \mathrm{mL}$ VC for another $1 \mathrm{~h}$. The values were normalized to the control levels. The data that are shown are the means \pm SE of four independent experiments. ${ }^{*} p<0.05,{ }^{* *} p<0.01$, compared with the control; $" p<0.05$ for comparisons between the indicated groups. (C) Bioluminescence analysis of HIF-1 $\alpha$ stability in ODD-Luc mice. After the ODD-Luc mice were given an intraperitoneal injection of 5-HMF $(100 \mathrm{mg} / \mathrm{kg})$ or vehicle (normal saline) for $1 \mathrm{~h}$ the mice were supplemented with VC $(140 \mathrm{mg} / \mathrm{kg})$ or with normal saline for another $1 \mathrm{~h}$. The data shown are the means \pm SE of four independent experiments. ${ }^{*} p<0.01$ compared with the vehicle, ${ }^{\#} p<0.05$ for comparisons between the indicated groups. The color bar indicates photons/(s/ $\mathrm{cm}^{2} /$ steradian), with minimum and maximum threshold values.

survival rate of mice under hypoxia was significantly increased by 5-HMF; however, VC supplementation apparently reduced the survival rate (Figure 6B).Thus, it is clear that the increased survival of mice induced by $5-\mathrm{HMF}$ under hypoxia is correlated with the increased stability of HIF- $1 \alpha$ by a reduction in the VC content.

Taken together, we demonstrated the interaction of 5-HMF with VC and the resulting reduction in VC content, which inhibited the activity of PHDs and ultimately stabilized HIF- $1 \alpha$ through blocking HIF- $1 \alpha$ hydroxylation-mediated degradation (Figure 7).

\section{DISCUSSION}

We first reported the role of 5-HMF against hypoxia in $2011(5,6)$; however, the potential mechanism had not yet been elucidated. By using ODD-Luc mice, which are an ideal model for identifying and characterizing small molecular inhibitors of PHD $(19,25)$, we found the role of 5-HMF in stabilizing HIF-1 $\alpha$. The ODD-Luc mice were generated by Safran et al. in 2006 (24). The mice provide a rapid noninvasive measurement of possible agonists of HIF-1 activity and are considered an ideal model that is suited for identifying and characterizing small molecular inhibitors of PHDs that would increase HIF-1 activity (25). We tested several compounds to find out the best one stabilizing HIF-1 $\alpha$ using these ODD-Luc mice. Ferulic acid and coumarin increased the activity of HIF-1 $\alpha$ in kidney but not in brain, and quercetin hardly played a role in stability of HIF- $1 \alpha$. Compared with the other three compounds, 5-HMF displayed a more significant role in stabilizing HIF- $1 \alpha$. The stabilized HIF-1 $\alpha$ was concentrated in the kidney area and part of the brain regions, and the stabilization was dose and time dependent. These results indicate that 5-HMF shows not only a strong role in stabilizing HIF- $1 \alpha$, but also a relatively wide distribution. In particular, the increased HIF- $1 \alpha$ activity in brain hints that 5-HMF can cross the blood-brain barrier, which suggests a more promising clinical application. To verify the effect of 5-HMF on HIF-1 $\alpha$, we further measured the protein expression of HIF-1 $\alpha$ in the cortex and kidney of ODDLuc mice by Western blot assay. In both the cortex and the kidney, 5-HMF increased HIF- $1 \alpha$ expression. Thus, we obtained a preliminary conclusion that 5-HMF improved HIF-1 $\alpha$ stability at the animal level.

By using hypoxia-sensitive PC12 cells, we confirmed the role of 5-HMF in stabilizing HIF- $1 \alpha$ and explored the potential HIF-1 $\alpha$ stabilization pathway of 5-HMF. The HIF-1 $\alpha$ protein was accumulated by $5-\mathrm{HMF}$ in a dose-dependent manner. To determine whether this effect was due to the enhanced HIF-1 $\alpha$ stability or due to the increased protein de novo synthesis, we detected the level of HIF- $1 \alpha$ mRNA by quantitative real- 
A

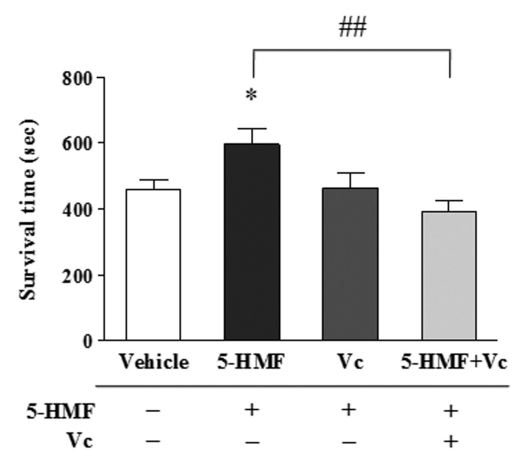

B

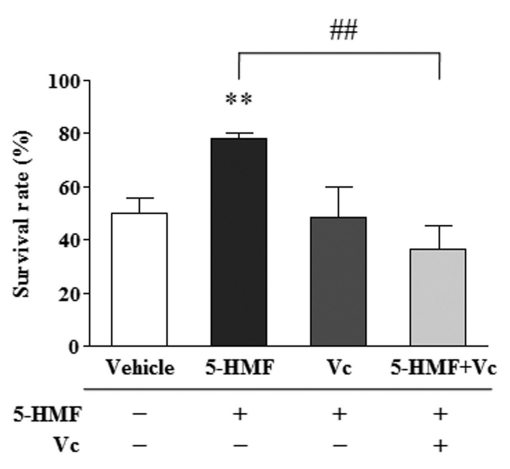

Figure 6. VC reversed the increased mice survival that was caused by 5-HMF under hypoxia. (A, B) The survival time and the survival rate under hypoxia. After the C57BL/6J mice were given an intraperitoneal injection of $5-\mathrm{HMF}(100 \mathrm{mg} / \mathrm{kg}), \mathrm{VC}(140 \mathrm{mg} / \mathrm{kg})$ or vehicle (normal saline) for $1 \mathrm{~h}$, which was followed by supplementation with vehicles or with VC ( $140 \mathrm{mg} / \mathrm{kg}$ ) for another $1 \mathrm{~h}$, the mice were exposed to sublethal acute hypoxia $\left(6 \% \mathrm{O}_{2}\right)$ in a hypoxia chamber, and their survival time was recorded. The data that are shown are the means \pm SE of three independent experiments. ${ }^{*} p<0.05,{ }^{* *} p<0.01$, compared with the vehicle; ${ }^{\# \#} p<0.01$ for comparisons between the indicated groups.

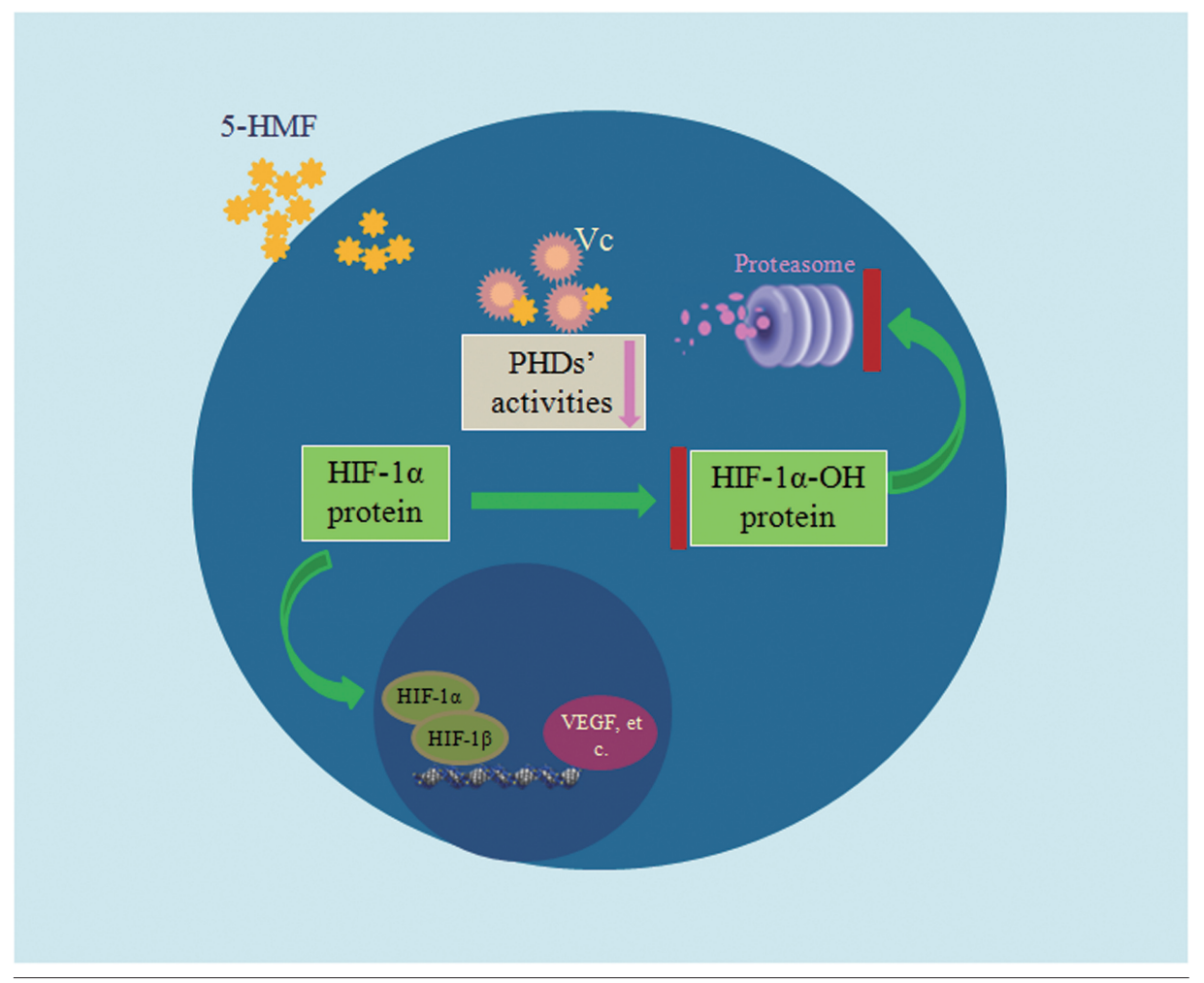

Figure 7. Model depicting the role of 5-HMF in stabilizing HIF- $1 \alpha .5-H M F$ enters cells in a dose-dependent manner. Then, 5-HMF rapidly interacts with VC and thereby reduces the VC content. PHD activities are declined because of the reduction in VC. HIF-1 $\alpha$ hydroxylation is inhibited because of the reduction of PHD activity, and thus, HIF- $1 \alpha$ cannot be degraded through the ubiquitin-proteasome pathway. Therefore, the HIF- $1 \alpha$ protein is stabilized and then translocates into the nucleus. In the nucleus, HIF- $1 \alpha$ combines with HIF- $1 \beta$ to form the heterodimeric transcription factor HIF-1, which regulates the transcription of its downstream genes, such as VEGF.

time PCR after the cells were treated with 5-HMF. Although there were no significant differences between 5-HMF and the control, there was a subtle trend of increasing HIF-1 $\alpha$ mRNA with increasing 5-HMF dosage. This result could indicate that the action of 5-HMF may not solely affect PHD function and may increase HIF-1 $\alpha$ levels.

In addition to regulating HIF-1 $\alpha$ stability, 5-HMF was also involved in promoting the nuclear translocation of HIF-1 $\alpha$. One viewpoint is that the rapid nuclear translocation of HIF- $1 \alpha$ is an efficient way to escape from proteasomal degradation (26); another viewpoint is that nuclear translocation is not necessary for HIF-1 $\alpha$ stabilization because both "nuclear" and "cytoplasmic" proteasomes are fully competent for HIF-1 $\alpha$ degradation in an oxygen-dependent manner (27). We believe that the nuclear translocation of HIF-1 $\alpha$ is one active mechanism of HIF- $1 \alpha$ and is a necessary process to form a heterodimer with HIF-1 $\beta$ in the nucleus. Perhaps HIF- $1 \alpha$ cannot be degraded in the nucleus once the heterodimer is formed. Regardless, the nuclear translocation of HIF- $1 \alpha$ is a premise to form the heterodimeric transcription factor HIF-1. In view of this result, we tested HIF-1 $\alpha$ translocation by using immunofluorescence staining. By confocal scanning, we directly observed the nuclear translocation of HIF-1 $\alpha$, which was promoted by 5 -HMF. The increased ratio of HIF-1 $\alpha$ nuclear translocation suggested the enhanced activity of HIF-1 $\alpha$. As some literature previously reported, once HIF- $1 \alpha$ is stable, this protein can rapidly translocate into the nucleus and activate the transcriptional activity of HIF-1 $(28,29)$.

To further assess whether the transcription activity of HIF-1 is activated by 5-HMF, we measured the mRNA expression of $V E G F$, which is a downstream gene of HIF-1, in the cortex and the kidney of ODD-Luc mice by RT-PCR. Consistent with the above results, 5-HMF improved the level of VEGF mRNA in both the cortex and the kidney. Thus far, we can say that 5-HMF promotes HIF-1 $\alpha$ 
stability, which therefore leads to the enhanced transcriptional activity of HIF-1.

The stability of HIF- $1 \alpha$ is determined by the activity of PHDs. To determine the mechanism by which 5-HMF stabilizes HIF- $1 \alpha$, we analyzed the interaction of $5-\mathrm{HMF}$ with $\mathrm{Fe}^{2+}, 2-\mathrm{OG}$ or VC in vitro, which determines the activity of PHDs. The result showed that 5-HMF did not react with $\mathrm{Fe}^{2+}$ or 2-OG but did react with VC. However, we still do not know the product that is generated from the reaction. In addition, we demonstrated that 5 -HMF could enter the cells in a dosedependent manner and reduce the intracellular VC content. This result suggests that 5-HMF reacted with $\mathrm{VC}$ in cells and thereby reduced the $\mathrm{VC}$ content.

Because 5-HMF reduced the VC content, could 5-HMF affect PHD activity? As we know, increased PHD activity can cause the prolyl hydroxylation of HIF- $1 \alpha$ and its subsequent degradation. In view of the difficulty in measuring PHD activity directly, we tested the level of hydroxylated 564 prolyl residues of HIF-1 $\alpha$ to indirectly reflect the activity of PHDs. We detected the reduced prolyl hydroxylation of HIF- $1 \alpha$ in those cells that were treated with 5-HMF, whereas VC supplementation reversed this effect of 5-HMF. Next, we verified the reverse effect of VC on 5-HMF-induced HIF-1 $\alpha$ stability separately in PC12 cells and in the ODD-Luc mice. Thus, we can speculate that PHD activity was inhibited by 5-HMF, which might be achieved through a reduction in VC content by the interaction of 5HMF with VC, and thus, the stability of HIF-1 $\alpha$ was improved. A recent finding that VC plays a significant role in supporting HIF-hydroxylase function and thereby modulates the cell survival response was consistent with our speculation (30).

To verify the effect of HIF- $1 \alpha$ stability on the protection against hypoxia, we used C57BL/6J mice to test the survival of mice under hypoxia. The survival time and the survival rate of the mice that were pretreated with $5-\mathrm{HMF}$ both increased, most likely because of the improved HIF-1 $\alpha$ stability by 5 -HMF. VC supplementation reversed this effect exerted by $5-\mathrm{HMF}$, which illustrated the role of HIF-1 $\alpha$ stability in hypoxia protection. This role is contrary to the role of VC in tumors, in which HIF-1 is an important regulator of the adaptation of the tumor to its hypoxic microenvironment, and VC administration can significantly reduce tumor growth rates (31). This observation indicates that the same mechanism can lead to opposite effects due to different pathophysiological states. In this study, pretreatment with 5-HMF increased the stability of HIF-1 $\alpha$ that subsequently translocated to the nucleus and activated the transcription of its downstream genes, including VEGF, EPO, GLUTs, and so on, which can enhance hypoxia tolerance (16-18,32) and ultimately increased survival time and survival rate of the mice. The reverse effect of VC supplementation on survival further confirmed that the role of 5-HMF in promoting survival under hypoxia was probably mediated by regulation on the HIF-1 $\alpha$ pathway.

\section{CONCLUSION}

In summary, we identified a molecular mechanism by which 5-HMF increases HIF-1 $\alpha$ stability in normoxia, which may play a critical role in the protection of 5-HMF against hypoxia. The regulation of HIF- $1 \alpha$ stability by 5 -HMF is an important pathophysiological mechanism that may provide a novel therapeutic approach to hypoxic diseases.

\section{ACKNOWLEDGMENTS}

This work was supported by the National Basic Research Programs of China (2012CB518200, 2011CB910800) and grants from the Natural Science Foundation of China $(81071066,81000856$ and 31271211).

\section{DISCLOSURE}

The authors declare that they have no competing interests as defined by Molecular Medicine, or other interests that might be perceived to influence the results and discussion reported in this paper.

\section{REFERENCES}

1. Bennet L, et al. (2012) Cell therapy for neonatal hypoxia-ischemia and cerebral palsy. Ann. Neurol. 71:589-600.

2. Talos DM, et al. (2012) The interaction between early life epilepsy and autistic-like behavioral consequences: a role for the mammalian target of rapamycin (mTOR) pathway. PLoS One 7:e35885.

3. Doyle KP, Fathali N, Siddiqui MR, Buckwalter MS (2012) Distal hypoxic stroke: a new mouse model of stroke with high throughput, low variability and a quantifiable functional deficit. J. Neurosci. Methods. 207:31-40.

4. Abdulmalik O, et al. (2005) 5-Hydroxymethyl-2furfural modifies intracellular sickle haemoglobin and inhibits sickling of red blood cells. Br. J. Haematol. 128:552-61.

5. Li MM, et al. (2011) The protective role of 5-HMF against hypoxic injury. Cell Stress Chaperones. 16:267-73.

6. Li MM, et al. (2011) The protective role of 5-hydroxymethyl-2-furfural (5-HMF) against acute hypobaric hypoxia. Cell Stress Chaperones. 16:529-37.

7. Liu Z, Chao Z, Liu Y, Song Z, Lu A. (2009) Maillard reaction involved in the steaming process of the root of Polygonum multiflorum. Planta. Med. 75:84-8.

8. Husoy T, et al. (2008) Dietary exposure to 5-hydroxymethylfurfural from Norwegian food and correlations with urine metabolites of shortterm exposure. Food Chem. Toxicol. 46:3697-702.

9. Okpala I. (2006) Investigational agents for sickle cell disease. Expert Opin. Investig. Drugs. 15:833-42.

10. Lin AS, et al. (2008) 5-Hydroxymethyl-2-furfural, a clinical trials agent for sickle cell anemia, and its mono/di-glucosides from classically processed steamed Rehmanniae Radix. J. Nat. Med. 62:164-7.

11. Li YX, Li Y, Qian ZJ, Kim MM, Kim SK. (2009) In vitro antioxidant activity of 5-HMF isolated from marine red alga Laurencia undulata in free-radicalmediated oxidative systems. J. Microbiol. Biotechnol. 19:1319-27.

12. Villela NR, Cabrales $P$, Tsai AG, Intaglietta M. (2009) Microcirculatory effects of changing blood hemoglobin oxygen affinity during hemorrhagic shock resuscitation in an experimental model. Shock. 31:645-52.

13. Jaakkola P, et al. (2001) Targeting of HIF-alpha to the von Hippel-Lindau ubiquitylation complex by O2regulated prolyl hydroxylation. Science. 292:468-72.

14. Ivan M, et al. (2001) HIFalpha targeted for VHLmediated destruction by proline hydroxylation: implications for O2 sensing. Science. 292:464-8.

15. Ke Q, Costa M. (2006) Hypoxia-inducible factor-1 (HIF-1). Mol. Pharmacol. 70:1469-80.

16. Bernaudin M, Tang Y, Reilly M, Petit E, Sharp FR. (2002) Brain genomic response following hypoxia and re-oxygenation in the neonatal rat: identification of genes that might contribute to hypoxia-induced ischemic tolerance. J. Biol. Chem. 277:39728-38.

17. Semenza GL. (2001) Hypoxia-inducible factor 1 : oxygen homeostasis and disease pathophysiology. Trends Mol. Med. 7:345-50. 
18. Semenza GL. (2011) Hypoxia-inducible factor 1 : regulator of mitochondrial metabolism and mediator of ischemic preconditioning. Biochim. Biophys. Acta. 1813:1263-8.

19. Wu LY, et al. (2010) The anti-necrosis role of hypoxic preconditioning after acute anoxia is mediated by aldose reductase and sorbitol pathway in PC12 cells. Cell Stress Chaperones. 15:387-94.

20. Institute of Laboratory Animal Resources (U.S.), Committee on Care and Use of Laboratory Animals. (1985) Guide for the Care and Use of Laboratory Animals. Rev. 1985. Bethesda (MD): NIH. 83 pp. (NIH publication; no. 85-23).

21. Livak KJ, Schmittgen TD. (2001) Analysis of relative gene expression data using real-time quantitative PCR and the 2(-Delta Delta C(T)) method. Methods. 25:402-8.

22. Page EL, Chan DA, Giaccia AJ, Levine M, Richard DE. (2008) Hypoxia-inducible factor1alpha stabilization in nonhypoxic conditions: role of oxidation and intracellular ascorbate depletion. Mol. Biol. Cell. 19:86-94.

23. Queval G, Noctor G. (2007) A plate reader method for the measurement of NAD, NADP, glutathione, and ascorbate in tissue extracts: application to redox profiling during Arabidopsis rosette development. Anal. Biochem. 363:58-69.

24. Safran M, et al. (2006) Mouse model for noninvasive imaging of HIF prolyl hydroxylase activity: assessment of an oral agent that stimulates erythropoietin production. Proc. Natl. Acad. Sci. U. S. A. 103:105-10.

25. Schmid T, Young MR. (2006) Lights on for low oxygen: a noninvasive mouse model useful for sensing oxygen deficiency. Mol. Interv. 6:20-2.

26. Tanimoto K, Makino Y, Pereira T, Poellinger L. (2000) Mechanism of regulation of the hypoxia-inducible factor-1 alpha by the von Hippel-Lindau tumor suppressor protein. EMBO. J. 19:4298-309.

27. Berra E, Roux D, Richard DE, Pouyssegur J. (2001) Hypoxia-inducible factor-1 alpha (HIF-1 alpha) escapes $\mathrm{O}(2)$-driven proteasomal degradation irrespective of its subcellular localization: nucleus or cytoplasm. EMBO. Rep. 2:615-20.

28. Kallio PJ, et al. (1998) Signal transduction in hypoxic cells: inducible nuclear translocation and recruitment of the CBP/p300 coactivator by the hypoxia-inducible factor-1alpha. EMBO. J. 17:6573-86.

29. Brahimi-Horn MC, Pouyssegur J. (2009) HIF at a glance. J. Cell Sci. 122:1055-7.

30. Kuiper C, Dachs GU, Currie MJ, Vissers MC. (2014) Intracellular ascorbate enhances hypoxiainducible factor (HIF)-hydroxylase activity and preferentially suppresses the HIF-1 transcriptional response. Free Radic. Biol. Med. 69:308-17.

31. Kuiper C, et al. (2010) Low ascorbate levels are associated with increased hypoxia-inducible factor- 1 activity and an aggressive tumor phenotype in endometrial cancer. Cancer Res. 70:5749-58.

32. Zhang Z, Yan J, Taheri S, Liu KJ, Shi H. (2014) Hypoxia-inducible factor 1 contributes to Nacetylcysteine's protection in stroke. Free Radic. Biol. Med. 68:8-21. 